\title{
Study on Prevalence of Ovine Fasciolosis in and Around Chole Woreda, Ethiopia
}

\author{
Hubad Hussien, Seifudin Kasim, Sufian Abdo, Kemer Kadi, Mukarim Abdurahaman \\ School of Veterinary Medicine, College of Agriculture and Veterinary Medicine (JUCAVM), Jimma \\ University, Jimma Town, Ethiopia
}

\begin{abstract}
A cross-section study was carried out from November, 2015 to march, 2016 with the aim determining the prevalence of on ovine fasciolosis in and around choleworeda. Fecal sample were collected from a total of 384 sheep of all age and sex. Sedimentation technique was used for the recovery of fasciola egg from fresh fecal. Sample from these animal examination 195 were positive with an overall infection rate of $50.8 \%$ significant different $(P<0.05)$, the highest infection rate was found in shaboshuli $(63.1 \%)$ and the lowest $(40.5 \%)$ in Ya'Igugu, through statically a significant different $(P<0.05)$. There was no statically significant different $(P>0.05)$ in infection rates between male and female animal. Infection rate in age group were significant difference $(P<0.05)$. In general, the study indicates that ovine fasciolosis is widely distributed disease with high prevalence rate in the study area and trategic use of helminthic should be to reduce pasture contamination with fluke's eggs.
\end{abstract}

Keyword: Coproscopy, chole werada, fasciolosis, prevalence, sheep

\section{INTRODUCTION}

In Ethiopia, agricultural is the mainstay of the country and also the major resource of the employment and income. About $85 \%$ of the population is live in the rural area and are primarily engaged in agricultural of the level hood of more than sixteen million $(60,000,000)$ people in the country (Abera, 1990).

Ethiopia has an extremely diverse topography a wide range of climatic features and a multitude of agro-ecological zone which make the country, suitable for different agricultural production system. This intern has contributed to the existence of the large diversity of farm animals, genetic resource in the country (Ahmed et al., 2007).

The diverse ecology makes Ethiopia the home for large population of different domestic and wide animal with considerable contribution to the national economy. The livelihood of both rural and urban, or sedentary postoral communities in the country is to a large extent associated with the previous out put down from this sector (Heinonen et al.,1995).

Sheep and Goat provide as much as $30 \%$ of meat and milk consumed in sub-Saharan Africa and found on small holding throughout the continents. Sales of sheep and goat and their products are a vital to source of cash, especially for small holders who do not has access to credit or farm income. Their small size, high reproductive capacity and rapid growth rate, makes small ruminated a more flexible, short-term from research and development agencies than have cattle (Hansen and Perry, 1994).

Benefit from sheep and goat production in Ethiopia remains marginal due to impact of prevalent disease, malnutrition and management constraints, parasitism including fasciolosis represents the major barrier determining the development of the sub sector (Malone et al 1998). Fasciolosis is a disease mainly of domestic ruminants and occasionally other domestic animal and man caused by liver flukes, parasites, Fasciola hepatica and fasciola gigantica. It is particularly important in cattle and sheep (Heinonen et al., 1995). Loss due to fasciolosis is associated with mortality, reduced growth rate, reduction in weight gain and unthriffines, reduction in working power, condemnation of large number of infected liver, increased susceptibility to secondary infection and expense due to control measure (Yilma and Malone, 1998). An estimate of economic loss due to ovine fasciolosis in the Ethiopia high land was made based on available data on mortality, weight loss, reduced 
productivity efficiency and liver condemnation at slaughter. The economic effects of fasciolosis were identified and models for estimating the financial loss presented ovine fasciolosis losses were estimated at 48.4 million in Ethiopian birr per year of which $46.5,48.8$ and $4.7 \%$ were due to mortality, productivity (weight loss and reproductive wastage ) and liver condemnation, respectively).

The world-wide losses in animal productivity due to fasciolosis were conservatively estimated at over US \$3.2 billion per annual. In addition fasciolosis is now recognized as an emerging human disease, the world health organization (WHO) has estimated that 2.4 million people are infected with fasciola, and a further 180 million are at risk infection (Anon,1995).

The risk factor of fasciolosis is determined by the number of infected lymnaied snail in the grazing area .The disease has a predictable seasonal pattern in regions were snails are active for only part of the year. Some lymnaied snails a more acquact habit than other but all are restricted to damp or wet envirestricted to damp or wet environments.

In general they prefer non acidic low lying swampy area with slowly moving water. But land with small streams, spring blocked drainage or spillage. The influence of watering particles on the transmission of fasciola among sheep in the Ethiopian high lands snails burrow into the soil to survive the dry period and release cercaria when free water is presented the later expands and contract depending on water availability construction works, such as road building may alter drainage patterns and disease risk improvement of peaty pasture by time application may increase risk by reducing soil acidity and allowing snail colonization (Radostitis et al., 2005)

The present study was, therefore, undertaken with the aim of generating valuable on ovine fasciolosis originating from different kebele's of chole and its surrounding.

Therefore, the objectives of this study were;-

- To study the prevalence $\mathrm{f}$ the fasciolosis and

- To find out associated risk factor of the ovine fasciolosis in chole town and its surroundings

\section{MATERIALS AND METHODS}

\subsection{Description of the Study Area}

The study was conducted in chole woreda and its surroundings, Arsi zone of Oromia regional state, southern east Ethiopia from November, 2015to march, 2016. Chole is one of the Arsi Zone woreda which located east to Asella town. The climatic condition of the woreda is divided into high land$48 \%$, wayena dega $-18 \%$, lowland $-22 \%$ and werch- $12 \%$ respectively. The topography of this areas includes plates, mountains and hills and its total land area is estimated to be 68200 hectares.

The woreda have a huge livestock population such as cattle 102,506, sheep 42,603, Goat 40,961, Horse 12,443 , Donkey 10,387 , Mule 4,526 , poultry 70,149 . The human population of the woreda is estimated to be 88,190 both urban and rural area.

The agricultural system and husbandry practice of the communities specially the farmers is mainly mixed farming system and extensive management system respectively. Even though, choleworeda contains a huge livestock population there are different types of livestock disease which includes the production and productivity rates of animals. The common disease are:-Blackleg, Pasteulosis, Lumpy Skin disease, New castle disease Rabies, African horse sickness HS, andendo-parasite and ectoparasite such as fasciola, lungworm, nematodes and mange mites, ticks, etc respectively.

\subsubsection{Study Animals}

The study animals were indigenous sheep kept under traditional extensive management system in Chole woreda and its surroundings. In the population there are animals of different age groups and body condition of both sex groups.

\subsubsection{Study Types and Sample Size Determination}

The study type was cross-sectional with multi stage sample method which was conducted from November, 2013 to march, 2014. The study was a cross-sectional study involving 384 animals (200, Female and 184; male sheep).The explanatory variables considered were the age, sex, body condition and management system of the study animals. 
The age was categorized in two. These sheep less than 4 months of age were grouped under young while these sheep above 4 month of age were grouped under adults. Body condition scoring was made according to Nicholson and Butter worth (1986).

\subsubsection{Sample Size Determination}

To determinate sample size a fasciola prevalence of $50 \%$ was taken into consideration as there is no previous study conducted in the area. The desire sample size for the study was calculating using formula given by Thrusfield, (1995) with 95\% confidential interval and at 5\% absolute precision .There for, a minimum sample size of 384 sheep was considered for this study.

$\mathrm{n}=1.96^{2} * \operatorname{Pexp}(1-\mathrm{Pexp}) / \mathrm{d}^{2}$

Where $n=$ require sample size

Pexp=expected prevalence

$\mathrm{CI}=$ confidential Interval $(95 \%)$

$\mathrm{d}=\mathrm{desired}$ absolute precision $(5 \%)$

\subsubsection{Sample Procedure}

Three representative sites including shaboshulli, Akiya Tulu egu and Ya'igugu were selected by judgment .Sampling unites where selected randomly. Approximately $10 \mathrm{gm}$ fecal sample was collected directly from the rectum using disposable plasmatic glove into screw capped universal bottles from each selected animals. Sample was preserved by $5 \%$ formalin solution to avoid hatching eggs. At the same time animal identity including age, sex, body condition, management system and study sites were recorded. Each sample was clearly labeled cross ponding to the identity of sample animals. At the end of every day sample collection fecal sample were transport to chole veterinary clinic and at the end of every week transport to asella regional veterinary laboratory for examination.

For examination and identification of adult of fasciola parasite, postmortem examination was done on animals slaughtered at chole municipal abattoir .In every visit animals which had flukes infested liver were examined.

\subsubsection{Data Management and Analysis}

All raw data that were recorded from this study were interred into Microsoft excel data base system and referenced with geographical location of the study area. Using SPSS computer programs data were summarized and analyzed. Chi-square (X2) test was used to determine the variation infection prevalence between sex and age. A 5\% significant level was used to determine whether there is significant difference between the parameter measures between the groups.

\section{RESUlT}

\subsection{Carpological Examination}

Over all prevalence from a total of 384 examined sheep fecal sample of the three districts in and around chole woreda,195 samples were found positive for fasciola eggs with in an overall prevalence of 50.8\%. The prevalence of fasciolosis recorded in the three associations(PAs)were $\mathbf{6 3 . 1 \% , 4 7 \% , 4 0 . 5 \%}$ is Shabo shuli, Akiya tulu egu and Ya'I gugu respectively. There were statically significance differences between the prevalence of fasciola eggs in the different study sites. $(\mathrm{P}<0.05)$

Table1. Prevalence of Ovine Fasciolosis on Site Basis

\begin{tabular}{|l|l|l|l|}
\hline PAs & No. Examinated & No. Positive & No. Prevalence (\%) \\
\hline Shabo shuli & 141 & 89 & 63.1 \\
\hline Akiya tulu egu & 117 & 55 & 47 \\
\hline Ya'I & 126 & 51 & 40.5 \\
\hline Total & 384 & 195 & 50.8 \\
\hline
\end{tabular}

Prevalence by age groups of animals; the infection rate between young and adult animals was compared. It was observed that the prevalence of fasciolosis was significantly higher in adult $(58.5 \%)$ than young (41.3) animals. 
Hubad Hussien et al.

Table2. Prevalence of Ovine Fasciolosis on Age Group Basis

\begin{tabular}{|l|l|l|l|}
\hline Age Gruop & No. Examinated & No. Positive & No. Prevalence (\%) \\
\hline Young & 172 & 71 & 41.3 \\
\hline Adult & 212 & 124 & 58.5 \\
\hline Total & 384 & 195 & 50.8 \\
\hline
\end{tabular}

Prevalence by sex groups; Over all prevalence fasciolosis in male and female sheep was $44 \%$ in male and $57 \%$ in female. Although the prevalence was relatively higher in female $(57 \%)$ sheep than in male sheep $(44 \%)$. The difference was not statistically significant $(\mathrm{P}>0.05)$

Table3. Prevalence of Ovine Fasciolosis Sex Basis

\begin{tabular}{|l|l|l|l|}
\hline Sex & No. Examinated & No. Positive & No. Prevalence (\%) \\
\hline Female & 200 & 114 & 57 \\
\hline Male & 184 & 81 & 44 \\
\hline Total & 384 & 195 & 50.8 \\
\hline
\end{tabular}

\section{DiscuSSION}

\subsection{Prevalence and Associated Risk Factor}

The result of the present study has revealed prevalence of 50.8\%(195/384) in the study area which is comparable to other workers in different region of country such as Michael (2003) with prevalence of $51 \%$ of Debrezeit (mid altitude )and Yilma (1985) with a prevalence of $49 \%$ in Holeta

The result of the present study was relatively medium one when compared with the reports from different parts of the country. The difference in the prevalence might be related to the variation in the agro-climate condition management system in the different study areas, including altitude, rainfall, temperature, humidity and management system of the sheep. This prevalence in the study area may be attributed to the presence of conductive ecological factors for the snail intermediate host and the parasite (fasciola) in the study area, feature of the land escape being plain with "poor drainage, heavy dark brown clay soil (With slight acidic $\mathrm{PH}$ ) which has high capacity of water retention with annual over flooding during the rainy season leaving pockets of water bodies and is mostly marsh area for long period during the dry season. Barcha River, slowly flowing rivers and swampy parts of the river border the area such ecological conditions are considerable for breeding and survival of the intermediate host snails and the parasite (Graber and Dans, 1974 and Argaw, 1998).

Both of the study areas were having a prevalence of $63.1 \%$ (Shabo shuli), $47.0 \%$ (Akiya tulu egu) and $4.5 \%$ (Ya'I gugu) with statistical difference $(\mathrm{P}<0.05)$. This significance difference might be due to the different in the epidemiology of the three areas that is the high land nature of Shabo shuli and again have swampy and marsh area, Akiya tulu egu is somewhat similar to shabo shuli the nature of area, The high land nature of Ya'I gugu ,however ,this area have less watery bodies that means marsh area and swampy area.

The study related that prevalence of ovine fasciolosis become high following the increase of age in sheep .In other word, the younger the age the lower the prevalence and the older the age the higher it will be (table 2) So that significant variation in prevalence of ovine fasciolosis of different age group were observed $(\mathrm{P}<0.05)$.This is certainly because of that adult animal have repeatedly exposed to flukes infection than young's similar results has been reported by Aseged (1981).

When the prevalence of ovine fasciolosis was compared between female $(57 \%)$ and male $(44 \%)$ sheep. These was no statically significant difference $(\mathrm{P}>0.05)$ in prevalence between females and male. This shows that sex seems have no effect on the prevalence and both sex are equally susceptible and expose to the disease. And this might also be due to grazing of both groups in similar fasciola contaminated pasture land. Similar result has been reported by (Graber and dans, 1974 and Argaw, 1998).

\section{CONCLUSION AND RECOMMENDATION}

In general, it can be concluded that fasciolosis is one of the major obstacle for livestock development in Ethiopia by inflecting remarkable and indirect losses at different part of the country where its occurrence is closely linked to the presence of biotype suitable for the development of snail intermediate host. The present study indicates that ovine fasciolosis is widely distributed disease with high prevalence rate in the study area. 
From the result we can conclude that:-

Integrated approach, which is combination of selective chemotherapy and selective vector control, should be considered more practically and economically feasible.

Education of farness with economical significance and control methods of this distance was forwarded.

Strategic use of helminthic should be performed to reduce pasture contamination with fluke's eggs.

$>$ Further study on the control aspect of the disease should be done to reduce the economic impact of fasciolosis in the study area.

$>$ It is impossible to treat all water bodies due to huge cost implication and environmental hazards. Hence, control of snail population should be selective directed toward the main watering point (transmission site or contact points) at specific time.

\section{ACKNOWLEDGEMENTS}

The author acknowledges Jimma University College of Agriculture and Veterinary Medicine; laboratory of Parasitolgy for the facility provision and Chole worada for financially supports this study.

\section{REFERENCES}

Abera B (1990). Prevalence and Economic Significance of Fasciolosis in "Neur cattle" slaughtered at Dembi-dello slaughterhouse. DVM Thesis, Faculty of Veterinary Medicine, Addis Ababa University, Debre Zeit, Ethiopia, pp. 21-22.

Ahmed E.F, Markvichitr K, Jumwasorn S, Koonawoothtthin S, Achoothesa Jittapalapong S (2007). Prevalence of Fasciola Species infections of sheep in the middle awash river basin, Ethiopia. Southeast Asian J. trop. Med. Publ. health, 38:51-52.

Anon., 18 March 1995. Resistance to fluke drug found on Sligo farm, Irish Farmer's J. 2.

Argaw K (1998). Epidemiology of Bovine Fasciolosis in Galama Awraja (ARSI). In: Ethiopian Veterinary Association Proceeding of the Twelfth Conference. 11-12 June, Addis Ababa, Ethiopia, pp: 35-42.

Aseged,G.,1981.The Study of Ovine helminthiasisin Awassa and effects of Control with Nilzan .M.sc. Thesis,faculty of Sciences ,Addis Ababa University ,AddisAbaba, Ethiopia, p.45.

Graber M, Daynes P (1974). Molluscs: human and animal vectors of trematodoses in Ethiopia. Review animal Breeding and Veterinary medicine of the Tropical Countries 27: 307-322.

Hanson J, Perry B (1994). The Epidemiology, Diagnosis and Control of Helminth Parasites of Ruminants. A Hand Book, Food and Agricultural Organization of the United Nations, Rome, Italy, pp. 72- 89.

Heinonen, M., G. Pute and S. Kebede, (1995). The anti-parasitic treatment against fasciolosis on cross breed and Zebu Cows in Ethiopia, World Review of Animal Production, 82: 40-46.

Micheal GBB (2003). Treatment and Control of liver fluke in sheep and cattle, Technical notes, November, 2003, West mains roads, Edinburgh, pp. 34-45.

Radostits,O.M.,Blood,D.C. and Gray.D.C. 2005. A text book of the disease of cattle, sheep, Goats, PigsandHorse: Veterinary Medicine $8^{\text {th }}$ ed.Bailliere, Tindall, London, UK. Pp: 1015-1026

Thrusfield M (2005). Veterinary Epidemiology. 2ed, UK, Blackwell Sci., pp. 228-247

Yilma J (1985). Study on Ovine Fasciolosis and Other Helminth Parasites at Hollota. DVM Thesis, Faculty of Veterinary Medicine, Addis Ababa University, Debre Zeit, Ethiopia, pp. 45

Yilma J, Malone JB (1998). A geographical information system forecast model for strategic control of Fasciolosis in Ethiopia. Veterinary Parasitol., 78: 103-127. 